\title{
BEGINNING AND THE END
}

A stimulating lecture by Peter Dews (on The Ideology of the Aesthetic by Terry Eagleton), followed by a convivial evening discussing it with friends Chris and Steven, was the prelude to this book. It was a couple of days after the lecture that Madan decided to write on 'identity', and during the summer of 1993 he completed the autobiographical section (these are the passages in italics at the end of alternate chapters). In writing this book, he was searching for a theoretical, as well as his personal, identity.

This was a particularly painful time for him in more than one way, as he was becoming aware of changes in his body. In September, a week before the conference in Madrid where he was invited to present a paper, he unexpectedly suffered a stroke. The stroke, according to him, was due to his lack of enthusiasm for travel. Fiercely independent, he made a fair recovery. Once again, there were other changes.

Like a thoughtful teacher, he prepared those around him. He would talk movingly of death - in the theatre, in films, of friends, of neighbours, and even his own. One evening, he seemed preoccupied: 'There are some things I will never be able to do again; I know I will never be able to run up the hills any more. I am grieving for my own death.'

Even as we waited for the ambulance, minutes before he died, he referred to himself as a 'fragmented subject'. But to many who knew him, his intellectual strength and commitment to his writing were anything but fragmented. I was astonished to find that the two features of the human subject - perpetual mobility and incompletion - carry on beyond physical death. The heterogeneous process of identity, the differences rather than the similarities, the gaps and the holes rather than seamless webs, are as much a feature of the dead as they are of the living. Madan would have been very interested in the continually changing relationship which he has to those who grieve for him. 
I have edited and presented the book as I hope Madan would have wanted. In many ways, even though we had discussed much of the work, I have felt inadequate and unprepared for the task. I accept the inadequacies on my part and hope that it still remains a very worthwhile book.

Tasneem Raja 